\title{
PROBLEMS OF OPERATION AND MAINTENANCE OF UNDERGROUND CABLES
}

\author{
BY JOHN L. HARPER
}

\section{Abstract OF Paper}

The scarcity and high cost of transmission materials demands that the transmission capacity of electric underground cables be increased to a maximum.

The causes of failures of cables are analyzed and the conclusion drawn that overheating is the most important for consideration.

Methods of removal of heat from the cables are considered, and recommendations made for flooding the conduit with water, in order that the copper in underground lead-covered cables may approach the transmitting capacity of aerial cables. feel loath to meet increased demands by the purchase of new cables at the present inflated prices, when it is not known that either demands for power or the increased prices of cables will be permanent. It, therefore, now often devolves upon the operating engineer to devise ways and means for working present installations to a capacity much greater than they were supposed to have.

Cable manufacturers have endeavored, from their experience, to give the purchaser some idea of the carrying capacity of the cables sold, but the first hand experience of the manufacturers usually ends with the delivery of the cable; hence the data and information given out have about the same relative reliability as those furnished by generator manufacturers for the capacity of generators in the days when such capacity was rated on the temperatures of the outflowing air instead of the temperatures of the inside hottest parts of the coils.

The fundamental causes of cable break downs have not been differentiated from local causes, as data and information acquired by individual cable manufacturers have usually been influenced by local conditions of installation and use, with the result that the fundamentals have not been clearly emphasized 
and users with varying local conditions have received much misinformation.

For instance, many of the largest distributing systems using underground cables are in large cities where a very low load factor exists and there is a relatively small concentration of power delivery through any one conduit. Under these conditions, cables would naturally be given a higher rating than would be considered for places where they operate under a much higher load factor, as in the case of power distribution having the characteristics of the one with which the writer is connected, where the yearly load factor is in excess of 91 per cent and the daily load factor is in excess of 98 per cent. It is apparent that with this high load factor, cables have no chance to use off peak

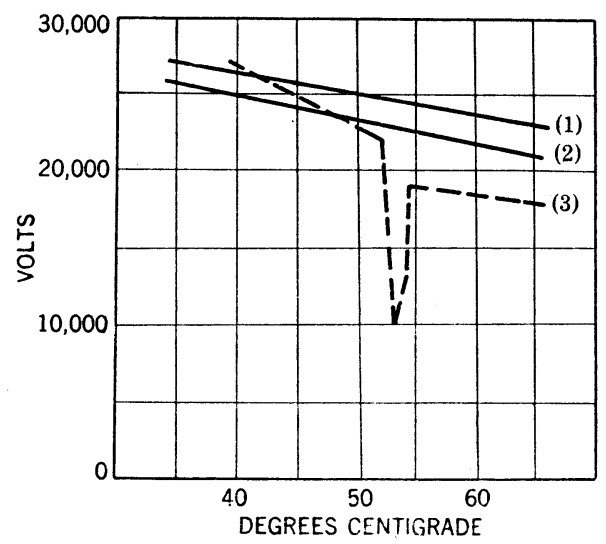

Fig. 1-(1) Joint Compound, (2) Cable Oil, (3) Mixture of 1 to 1 Joint Compound and Cable Oil

periods to dissipate the heat accumulated during peak periods. The concentration of a large number of cables in one conduit also has a direct influence on their total capacity.

Assuming cables to be made of good material and with good workmanship and design, I venture to propose the following as the fundamental causes of failure, viz.: Joint troubles, mechanical injury to lead sheaths, and overheating.

\section{Joints}

Under this heading may be noted:

1. Those troubles which arise from improper making of the joint, due to improper workmanship, poor material, inexperience, etc., the remedy for which is principally accumulation of knowledge by actual experience and practise. 
2. The incorporation of a joint filling compound that has not the same characteristics as the insulating compound used in the cable itself.

Cable insulation compounds are nearly always of a light color, while joint compounds are usually black. The mulatto combination of these two materials (each of which may be of the highest quality in its own clear unadulterated state) may produce a mixture having very different insulating characteristics from either of the original compounds. In the writer's experience, one whole system of cables had to be replaced on account of break downs in the vicinity of the joint wherever the cable insulation and the joint compound mixed. At that time a test was made of the insulating characteristics of the mixture for different temperatures and it was found that, while neither of the compounds in their clear form showed an insulation break down within the operating temperatures, the mixture did, and the curves in Fig. 1 show the relative conditions found to exist.

In a case like this, the operating engineer, being unable to wrench the secrets of the nature of the component parts of the insulating materials from the manufacturing company, was obliged to make further requirements of the cable manufacturer to the effect that he furnish a joint compound which would not show this objectionable effect. As the reinstallation of the cables under this method of procedure proved satisfactory and lasting, it has been assumed that in the privacy of the manufacturer's laboratory such changes were made in the joint or cable compounds that they maintained the high insulating characteristics even in the mixture.

Some expert joint makers contend that, if, in the handling of cables either at the factory or in the manhole, they are cut and allowed to hang down and bleed slightly, a bubble of air is liable to get into the cable, replacing the fluid which has bled. This bubble causes no disturbance until the cable is in operation and thoroughly heated up, when it may, by expansion, displace insulating compound and decrease the insulation at some special point, causing a slight leak of current with the resultant charring of the insulating materials and the production of a hot spot, whose temperature soon passes beyond the current resisting characteristics of the insulating material. This form of trouble often proves very elusive, as, in the case of the hot spot, as noted, if the cable is taken out of commission, cooled and again started up, the trouble may have moved several feet from the first loca- 
tion, or may still be present in the cable even if the original hot spot is cut out.

\section{Mechanical Abrasions}

In regard to mechanical abrasions of lead sheaths, these troubles are positive and must show themselves sooner or later. The writer is not aware of any means of overcoming these troubles in cases where due care has been taken in the insulation of the cable, except to let nature take its course. If the conditions surrounding the operation of the cable are such as to force the early determination of these mechanical faults, the assurance of future continuous operation is greatly increased.

\section{OverheATING}

The production of heat within the cables is a direct function of the square of the current transmitted as represented by the $I^{2} R$ losses; and also of any dielectric loss, which is a function of the voltage and temperature of the insulating materials. Any heat produced in the cable must be dissipated through the insulating materials, the protective sheath, the conduit structures, and the surrounding medium, if the cables are to be kept at a temperature within the range necessary to maintain their insulating characteristics.

The paper of paper-insulated cables belongs to that class of materials whose insulating value decreases with the rise of temperature; therefore, within working limits, the cooler the cable is kept the less the dielectric loss.

An instance of the destruction of paper insulation under high temperatures was noted in taking out a length of cable in which a section, at least fifty feet from where any known trouble had existed, was found where the paper insulation had practically disappeared. The three conductors holding their relative positions for about two feet, the lead sheath being fully intact but only half filled with ashes from the destroyed insulation. This cable, while in operation had given no trouble at this place on a 12,000 -volt working circuit.

The problem, therefore, resolves itself into a control of the dielectric loss and into an even and rapid dissipation of all heat produced within the cable. The retention of a constantly produced heat, no matter how small, would result in the building up of temperatures not only such as to destroy the insulating characteristics of the cable structures, but to destroy the cable itself. 
It is apparent that the area of obstruction to rapid dissipation of heat from the cable or conduit may not be in the cable itself or in the conduit structures, but may be a factor of the quality and condition of the earth surrounding the conduit; thus, a cable system installed under the sod at the side of a paved street may have a very different radiation coefficient from a similar conduit under the pavement of the same street.

In a paper by Mr. L. E. Imlay in 1915 this matter was brought up, and the suggestion made of dampening the earth on the outside of the conduit by means of porous tile laid in the ground outside, which, undoubtedly, is a step in the right direction.

In the writer's experience, a 12,000-volt, 3-conductor, 4-0 cable was found to transmit 190 amperes per leg easily when the conduit contained but one cable, while this same cable could transmit only 140 amperes per leg with the same rise of temperature through the same conduit when other similar cables had been added and were all connected in parallel. This would indicate that, in the particular instance noted, which was through clay soil and under a paved street, the obstruction to the dissipation of heat was in the earth surrounding the conduit structure. It was also noted that in this conduit, which was made up of nine ducts, an installation of eight cables in the outside ducts would transmit practically the same amount of power for the same rise of temperature as would be transmitted when the ninth cable was installed in the central duct. This indicates that any conduit has a total carrying capacity dependent upon the exterior surface of the conduit structure in contact with the surrounding earth. In Niagara Falls, under paved streets, in clay soil, and without artificial cooling, the capacity of any one conduit system is restricted to approximately 30,000 horse power.

That a cable may for a short time, without permanent injury carry power far in excess of its ordinary capacity was shown by a case where seven cables were furnishing power to a customer. A short circuit occurred that opened the breakers on six of these but the seventh failed to open. The needle of the dial on the instrument of the switchboard not being in sight, the operator did not notice that it had disappeared at the upper end of the scale, and he, therefore, left the cable in circuit while waiting advice from the plant to again put on the power. This not being received in the ordinary time, he called up and found that the customer was not cut off. An examination of the recording wattmeter indicated that the seven cables were delivering 
approximately $22,000 \mathrm{kw}$., that when the six were opened the power dropped to $18,000 \mathrm{kw}$. and gradually ran down during a time of 17 minutes to $9,000 \mathrm{kw}$., at which time it was taken out of service by the station operator. On examining this cable in the conduit it was found to be extremely hot and with several of the joint sleeves broken from internal pressure of compounds or gases. Upon cooling it down, filling up and resealing the joints, the cable was again put in operation and has been doing its work satisfactorily for four years.

In a recent construction of a hydroelectric power plant a saving of $\$ 500,000$ was made on the first cost by adopting a speed of $300 \mathrm{rev}$. per min. instead of $180 \mathrm{rev}$. per min.; therefore, why should not a similar effort be made to decrease the first cost of conduit and cable distributions of power by speeding up the dissipation of the heat formed by the $I^{2} R$ losses, at least to the point where in any cable system, the power value of the $I^{2} R$ losses may be made to balance the operating expense of increased construction and installation.

It is, therefore, suggested that the dissipation of heat by water be applied to new and permanent construction and that, in places where such construction is possible, conduit systems should be built so that the ducts can be flooded with water and cables operated under practically submarine conditions. Bare copper wires in aerial transmission lines now carry approximately twice the current that is carried in the corresponding conductor of an underground paper-insulated cable and, if the lead sheath of the cables were kept at a temperature below 60 deg. cent. by the presence of water, the carrying capacities of underground cables could be made to nearly approach that of bare aerial conductors.

The rapid and definite dissipation of the heat from the cables with water immediately surrounding them would not only greatly increase the carrying capacity of any particular cable or of a particular conduit system, but would decrease possibilities of cable trouble from all other causes except mechanical injuries of the lead sheath. 